\title{
Identificação de bactérias presentes em biofilmes de superfícies metálicas
}

\author{
Identification of bacteria present in biofilms of metal surfaces
}

Carlos Henrique Lopes Rocha'; Geovane Santos Muniz¹; Flaviane Maria Galvão Rocha ${ }^{1}$

Resumo. Objetivos: Considerado a importância dos biofilmes, o presente trabalho teve como objetivo avaliar as características da comunidade bacteriana existente em biofilmes associados a superfície de torneiras dispensadoras de água potável. Material e métodos: As amostras foram coletadas na abertura das torneiras, células foram semeadas, contadas e submetidas a coloração de Gram, testes de assimilação de carbono (BIOLOG) e Rugai. Resultados: Com o presente trabalho foi possível visualizar tanto bactérias Gram-positivas quanto negativas e quantificar as unidades formadoras de colônias por swab (UFC/Swab) encontradas em cada dispersador de água potável. Conclusões: As bactérias encontradas utilizam diversas fontes de carbono disponíveis para produção de nutrientes que neceita para sua sobrevivência, o método escolhido foi eficiente para classificação das bactérias encontradas.

Palavras chaves: biofilmes, superfícies metálicas, bactérias

Abstract. Objectives: Considering the importance of biofilms, this study aimed to evaluate the characteristics of the bacterial community existing in biofilms associated with the surface of drinking water dispensing faucets. Material and methods: Samples were collected at the opening of the taps, cells were seeded, counted and submitted to Gram staining, carbon assimilation tests (BIOLOG) and Rugai. Results: With the present work it was possible to visualize both Gram-positive and negative bacteria and to quantify colony-forming units by swab (UFC / Swab) found in each drinking water disperser. Conclusions: The bacteria found use several sources of carbon available for nutrient production that is necessary for their survival, the method chosen was efficient for the classification of the bacteria found.

Keywords: biofilms, metal surfaces, bacteria

\footnotetext{
${ }^{1}$ Discente do Programa de Mestrado em biologia Parasitária- laboratório de Microbiologia aplacada da Universidade CEUMA - Campus Renascença. Universidade CEUMA, Maranhão
} 


\section{Introdução}

Remonta ao ano 98 A.C. por Lucretius a referência a seres vivos muito pequenos, mas que causavam doenças ${ }^{1,2}$. Contudo foi a partir do século XIX por Koch, o início da associação direta entre bactérias a as doenças ${ }^{2,3}$. Desta forma, a presença desses microrganismos seria a causa provável de muitas das patologias que afetavam a população².

Algumas bactérias são benéficas para seu hospedeiro, outras são patogênicascas causando graves doenças ${ }^{4}$.As infecções bacterianas ocupam lugar de destaque nas patologias humanas, as do trato urinário surgem em segundo lugar logo após as infecções respiratórias ${ }^{2,5}$.

Bactérias são organismos unicelulares procariontes, podem ser encontradas isoladas ou formando biofilmes ${ }^{6}$, estes são formados por colônias de bactérias que ao entrar em contato com determinada superfície podem aderir de forma irreversível, formando uma matriz polimérica contendo diferentes compostos, como exopolissacarídeos, proteínas e ácidos urônicos ${ }^{7}$. Nesta condição ocorre a proteção de toda a comunidade microbiana, devido à diminuição da difusão e transporte de agentes antimicrobianos para 0 interior da matriz onde se concentram as células microbianas ${ }^{3}$. Praticamente todas as superfícies podem ser colonizadas por bactérias, mas o processo de formação de biofilmes é facilitado de acordo com as características físicoquímicas da superfície a ser colonizada, superfícies apolares são facilmente colonizadas, pois apresentam características que facilitam a aderência do biofilme no local ${ }^{8}$. Nos processos infeciosos causados por biofilmes, a transmissão é feita pela dispersão das bactérias no meio, causando diversos focos de infecção local e sistêmica, pois resistem a respostas imunológicas do hospedeiro e as bactérias existentes nos biofilmes são cerca de 1000 vezes mais resistentes aos antibióticos convencionais ${ }^{9}$.

A morfologia bacteriana é fundamental para a sua identificação ${ }^{10}$. A coloração diferencial de Gram classifica as bactérias em dois grupos: Grampositivas e Gram-negativas ${ }^{11}$. A reação das bactérias à técnica de Gram é relacionada diretamente à composição química, estrutural e a permeabilidade da parede celular ${ }^{11}$.

A parede celular das bactérias Gram-positivas é constituída de uma camada espessa composta por peptídioglicano, responsável pela sua rigidez, já nas gram-negativas, a camada de peptidioglicano é mais fina, relativamente, que consequentemente confere uma maior fragilidade ${ }^{11}$.

Outro método utilizado na identificação de bactérias que está associado ao estudo da estrutura funcional, é a avaliação do perfil metabólico das comunidades por meio do sistema EcoPlate, que mede a intensidade de utilização de diferentes fontes de carbono ${ }^{12}$.

O Biolog EcoPlate contém as fontes de carbono mais úteis para a análise um total de 31 fontes, estas são repetidas 3 vezes para gerar repetições possibilitando estudo estatístico dos dados obtidos ${ }^{13}$. Chama-se impressão metabólica o padrão de reações características realizadas por comunidades microbianos, estes padrões de reação de impressão digital rapidamente e facilmente fornecem 
uma grande quantidade de informações de um único Biolog MicroPlate ${ }^{13}$.

As enterobactérias são bacilos gram-negativos, não esporulados, com motilidade variável, oxidase negativa, e crescem em meios básicos, meios ricos e meios seletivos 13. São anaeróbios facultativos, fermentam a glicose com ou sem produção de gás, são catalase positivos, e reduzem nitrato ${ }^{14}$. São encontrados nos mais variados ambientes, como a $K$. pneumoniae, outras são de exclusividade humana como Salmonella typhi, Algumas são consideradas enteropatogênicas por causarem infecções gastrintestinais, como a Salmonella typhi, Shingella spp, Yersina enterocollica e vários sorotipos e E.colit ${ }^{14}$.

As enterobactérias representam $80 \%$ ou mais de todas das gram-negativas de importância médica ${ }^{15}$. São responsáveis por mais da metade das causas de infecção urinárias e $50 \%$ das septicemias $^{14}$.

As provas de identificação das enterobactérias consiste em sistemas simplificados de provas bioquímicas. Uma dessas provas é o Rugai modificado que consiste em nove provas em apenas um tubo de ensaio, que são: indol, fermentação da sacarose, glicose, rodução de gás triptofanase, uréia, $\mathrm{H}_{2} \mathrm{~S}$, lisina e motilidade $^{14}$. O meio Rugai é prático para a inoculação e de baixo custo. Sua desvantagem é a dificuldade de interpretação das provas, exigindo muita experiência. Algumas espécies de Enterobacter, gênero Serratia, gênero e espécie de Pseudomonas precisam-se de provas complementares para correta identificação ${ }^{14}$. Considerando a importância da correta classificação e identificação das bactérias em estudo, o presente trabalho teve como objetivo identificar bactérias isoladas de superfícies metálicas de dipersadores de água com auxílio do teste de Gram, Rugai e Biolog.

\section{Material e métodos}

Caracterização de bactérias
presentes em biofilmes de
superfícies metálicas ou inanimadas

As amostras foram coletadas com auxílio de Swabs estéreis umedecidos com salina estéril $(0,9 \%)$ realizando 10 movimentos circulares concêntricos na abertura das torneiras, uma de um bebedouro e a outra de um banheiro. Em seguida, os Swabs foram introduzidos em tubos estéreis contendo $5 \mathrm{ml}$ de solução salina $(0,9 \%)$, devidamente identificados. Os tubos foram agitados por 1 minuto e foram realizadas diluições $\left(10^{0}, 10^{-1}, 10^{-2}\right.$ e $\left.10^{-3}\right)$. Para cada diluição foram inoculadas cerca de $100 \mu \mathrm{L}$ sobre a superfície das placas com auxílio de uma alça de Drigalski ou pérolas de vidro contendo os meios de cultura ágar MacConkey, ágar manitol salgado e ágar BEM (Agar Bile Esculina). Após 0 plaqueamento as placas foram incubadas a $35^{\circ} \mathrm{C}$ por 24 horas. Após período de incubação as colônias foram contadas (UFC/swab).

\section{Morfologia microscópica de bactérias e coloração pelo método de gram}

Foram utilizadas placas
contendo Escherichia roli,
Staphylococcus aureus como
controle, as placas contendo as
amostras obtidas do banheiro e do
bebedouro foram submetidas ao


teste. Foi realizado um esfregaço, este foi deixado secar a temperatura ambiente, em seguida foi fixado no bico de Bunsen. Depois, ao esfregaço foi adicionada solução de cristal violeta, acrescentado 5 gotas de solução de bicarbonato de sódio por 3 minutos. Após este período as amostras foram lavadas em água corrente, coberto com lugol por 2 minutos. O esfregaço foi lavado novamente, e descorado com acetona-éter e lavado novamente com água. Após a lavagem foi coberto com a solução de fucsina ou safranina por 30 segundos, lavado e deixado secar para ser examinado. Foi utilizada lente de aumento (100 x) para a observação.

\section{Teste de assimilação de carbono (biolog)}

Uma alíquota de $100 \mu \mathrm{L}$ foi transferida para cada poço diretamente em MicroPlates Biolog. $\mathrm{Em}$ seguida as placas foram incubadas a $35^{\circ} \mathrm{C}$ por 24 horas para posterior análise da mudança de cor em leitor de placa no comprimento de onda de $590 \mathrm{~nm}$. (Rugai)

\section{Identificação de bactérias}

Com o auxílio de um fio de platina, foi coletada uma amostra da colônia. Em seguida foram semeadas nos tubos contendo os 3 meios na seguinte ordem: Citrato, EPM e MILi. Deslizou-se a agulha pelo centro, estriando toda a superfície inclinada para inocular o meio de citrato, introduziu-se a agulha até o fundo do tubo e ao retirá-la, semeou a superfície do meio, enquanto o meio $\mathrm{MLi}$ foi semeado por picada central, até atingir o fundo do tubo (figura 6) . Após a inoculação os tubos foram incubados em estufa a $35^{\circ} \mathrm{C}$ por 24 horas.

\section{Resultados}

Dentre as diluições realizadas, foi possível realizar a quantificação das unidades formadoras de colônias por swab (UFC/Swab) apenas nas diluições $10^{0}$ e $10^{-1}$, destas houve crescimento variado nos meios utilizados, tal situação é melhor caracterizada na figura 1 e figura 2.

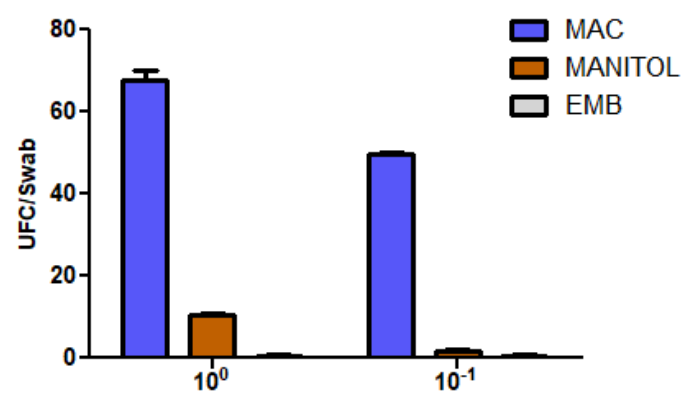

Figura 1. Unidades formadoras de colônias por swab (UFC/Swab) a partir de diluições da amostra coletadas no banheiro.

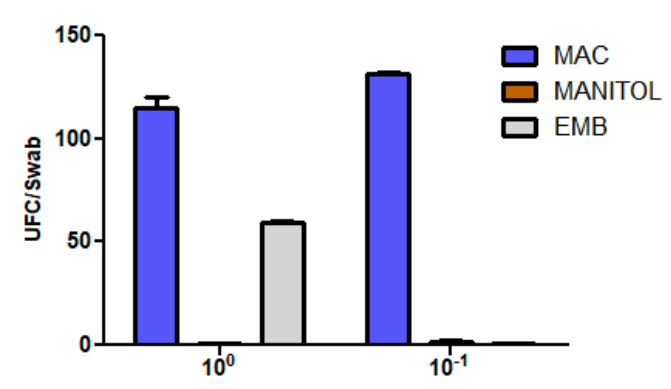

Figura 2. Unidades formadoras de colônias por swab (UFC/Swab) a partir de diluições da amostra de um bebedouro.

O método da coloração de Gram é baseado na capacidade das paredes celulares de bactérias Gram- positivas de reterem o corante cristal violeta no citoplasma durante um tratamento com álcool-acetona enquanto que as paredes celulares de bactérias Gram- negativas não o 
fazem, desta forma, as bactérias Gram- positivas coram-se de roxo e as Gram- negativas coram-se de vermelho.

Os resultados encontrados mostraram a prevalência de bactérias Gram positivas, mas foi possível entre as amostras, identificar bactérias gram-negativas. Foi possível verificar também a confirmação de que Escherichia coli quanto a coloração é gram negativa e Staphylococcus aureus grampositiva (Figura 3).

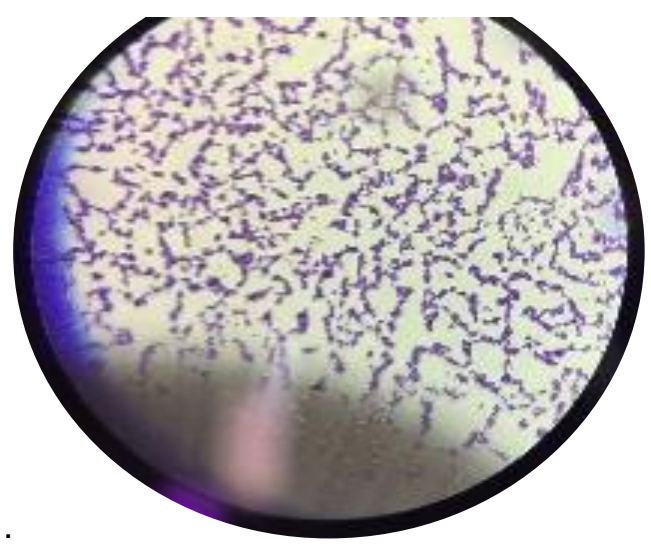

Figura 3. Staphylococcus aureus, obervada ao microcópio de luz após ser submetida a coloração de Gram, aumento de 1000 X

Após o tempo de incubação as placas, para 0 teste de assimilação de carbono, foram observadas e os poços que haviam mudado de cor foram catalogados (Figura 4) e o gráfico foi construído como ilustrado na figura 6 .

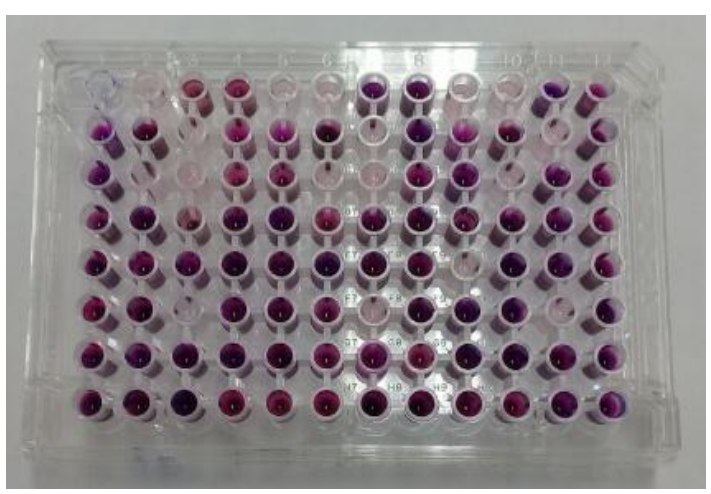

Figura 4. Teste de assimilação de carbono (ECOPLATE)

Rugae foi observado após o período de incubação os tubos foram retirados da estufa e os mudanças ocorridas foram observadas (Figura 5). Tabelas foram construídas com os dados coletados nas observações (Tabela 1 e tabela 2 ).

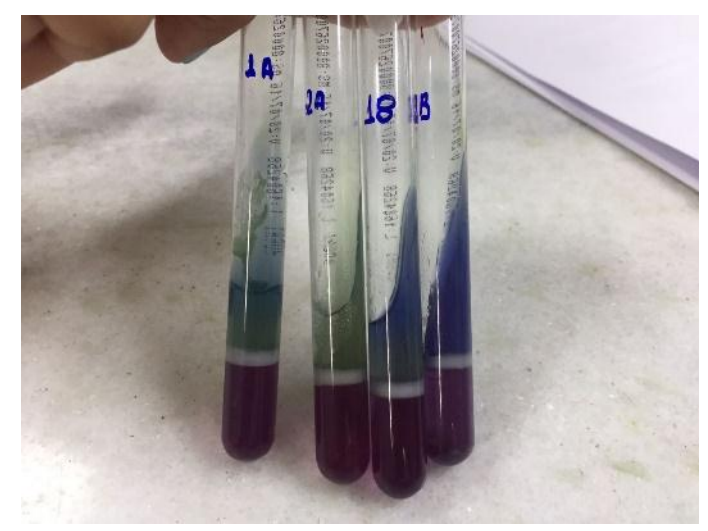

Figura 5. Teste Rugae. Crescimento bacteriano em diferentes condições. 


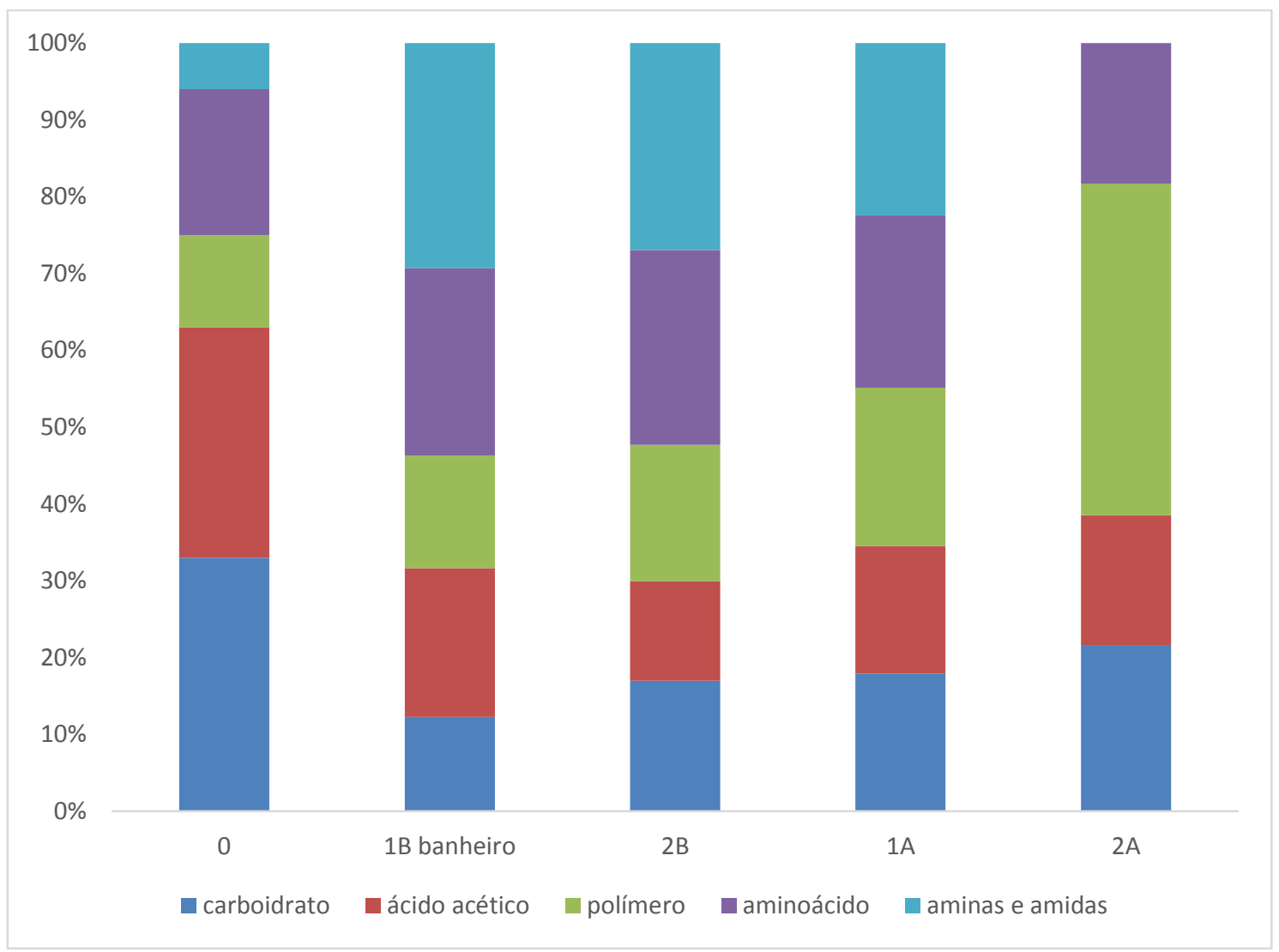

Figura 6. Isolados submetidos ao teste de assimilação de fontes de carbono. 0- Escherichia coli; $1 \mathrm{~B}$ e $2 \mathrm{~B}$-amostras provenientes de um banheiro; $1 \mathrm{~A}$ e $2 \mathrm{~A}$ - amostras provenientes do bebedouro.

\section{Discussão}

A formação de biofilmes em superfícies metálicas é um problema enfrentado em vários ambientes ${ }^{16,17,18,19}$, principalmente no ambiente hospitalar causando graves quadros de infecções ${ }^{19,20}$. $\mathrm{O}$ estabelecimento dos biofilmes é preocupante por ser um foco da dipersão bacteriana, dependendo do paciente e do microrganismo, pode levar a quadros graves, podendo até mesmo ocasionar o óbito do paciente ${ }^{19}$.

As torneiras dos banheiros por serem fonte de água utilizada para higienização das mãos, uma vez contaminada é preocupante ${ }^{21}$. No presente trabalho foi possível quantificar as bactérias isoladas torneiras do banheiro e bebedouro, a maior quantidade de células encontrada foi nas torneiras dos bebedouros, mostrando que a higienização desses dispersadores de água não está sendo realizada adequadamente, colocando em risco seus usuários, o relato da ocorrência de microrganismos em superfícies é de extrema importância ${ }^{16}$.

Foi realizada a coloração de Gram classificando as bactérias em positivas e negativas, estas são as mais patogênicas, uma vez encontradas em ambientes como essas torneiras também é preocupante, pois podem gerar quadros agravantes de infecção ${ }^{19}$.

A habilidade das bactérias formarem biofilmes em superfícies metálicas é um importante fator de virulência ${ }^{22}$. A detecção de iolados ambientais com esta capacidade é 
importante para uma estratégia de higienização mais eficiente desta superfícies, uma vez que quando realizada de forma ineficiente permitem que tornem-se fonte de contaminação ${ }^{23}$.

A classificação das bactérias em gram positivas ou negativa não é suficiente, provas bioquímicas adicionais são essenciais para se conhecer o perfil metabólico das bactéria colonizadoras dos ambientes que temos contato, pois sabendo disso podemos até mesmo associar à sua patogenicidade, pois uma vez em contato com 0 hospedeiro elas iniciaram a quebra de moléculas orgânicas, e demonstrando que possuem esta capacidade podem representar um problema para o tratamento ${ }^{19,24,25}$. Os testes realizados neste trabalho mostraram que os microrganismos encontrados são capazes de metabolizar diferentes fontes orgânicas a presença desses microrganismos mostra que devemos dar mais atenção a correta higienização desses ambientes.

\section{Conclusões}

Uma vez que, todos os passos e procedimentos necessários para o método de coloração de Gram foram realizados, os objetivos foram alcançados, pois tanto bactérias Gram-positivas, quanto Gramnegativas foram encontradas nas amostras do bebedouro e banheiro, visualizadas no microcópio óptico. É possível concluir que grande quantidades de unidades formadoras de colônias colonizadoras de superfícies metálicas, indicando

a contaminação.

Os microrganismos foram capazes de se desenvolver em superfícies metálicas utilizando diversas fontes de carbono. A classificação dos organismos encontrados nas amostras necessita de testes adicionais para identificação das espécies encontradas.

Tabela 1. Características identificadas após período de incubação em meio Rugai.

\begin{tabular}{cccccccccc}
\hline \multicolumn{10}{c}{ Condições } \\
\hline Isolados & Motilidade & Lisina & Indol & $\mathrm{H}_{2} \mathrm{~S}$ & Urease & Lactose & Gás & Sacarose & Glicose \\
\hline 1A & - & + & - & - & + & + & - & - & - \\
2A & - & + & - & - & - & - & - & - & - \\
1B & - & + & - & - & + & + & - & - & - \\
2B & - & + & - & - & + & + & - & - & - \\
\hline
\end{tabular}

Tabela 2 . Características identificadas após período de incubação em meio Rugai.

\begin{tabular}{ccccccccc}
\hline & \multicolumn{10}{c}{ Condições } \\
\hline Isolado & Triptofano & Citrato & Ureia & Motilidade & Indol & Gás & $\mathrm{H}_{2} \mathrm{~S}$ & Lisina \\
\hline $1 \mathrm{~A}$ & + & + & + & - & - & - & - & + \\
$2 \mathrm{~A}$ & + & - & - & - & - & - & - & + \\
$1 \mathrm{~B}$ & + & + & + & - & - & + & - & + \\
$2 \mathrm{~B}$ & + & + & - & - & - & - & - & + \\
\hline
\end{tabular}




\section{Referências}

1. Nutton, V. The seeds of disease: an explanation of contagion and infection from the Greeks to the Renaissance. Med Hist. 1983;27:134.

2. Rodrigues, F.J.; Barroso, A.P. Etiologia e sensibilidade bacteriana em infecções do tracto urinário. Rev. Port. Sau. Pub. 2011; 29: 2.

3. Gradmann C. Robert Koch and the pressures of scientific research: tuberculosis and tuberculin. Med Hist. 2001;45:1-32.

4. Santos, N.Q. A Resistência bacteriana no Contexto da Infecção hospitalar. Contexto Texto - enferm. 2004;13.

5. Camargo, C.B.; Pedro, C.C.; Lourenço, D.S.; Gironi, R.H; Martinez, R. Infecção de vias urinárias na comunidade de Ribeirão Preto: Etiologia, sensibilidade bacteriana a antimicrobianos e implicações terapêuticas. Medicina. 2002; 35:173-8.

6. Burton, G.R.W.; Engekirk, P.G. Microbiologia para ciências da saúde.. Rio de Janeiro, Ed.7, Guanabara Koogan, 2005.

7. Li, Y. H., \& Tian, X. Quorum sensing and bacterial social interactions in biofilms. Sensors 2012; 12(3): 2519-38.

8. Reid, Departament of microbiology, the University of Western Ontario, and Lawson Research Institute, London, Ont, Canadá, 1999.

9. Nitschke, M. Araújo, L.V. Costa , S.G.V.A.O. Pires,R.C. , Zeraik , A.E., Fernandes, A.C.L.B. Freire, Contiero ,D.M.G. J. Surfactin reduces the adhesion of food-borne pathogenic bacteria to solid surfaces. Lett Appl Microbiol. 2009; 49(2): 241-7.

10. Van Teeseling, M., De Pedro, M. A., \& Cava, F. Determinants of Bacterial Morphology: From Fundamentals to Possibilities for Antimicrobial Targeting. Frontiers in microbiology. 2017; 8.
11. Salton, M.R.J. Studies of the bacterial cell wall. IV. The composition of the cell walls of some Gram-positive and Gram-negative bacteria. Biochim. et Biophysica Acta, Amsterdam, 1953. p.512-523.

12. Souza, L.M.; Schlemmer, F.; Alencar, P.M.; Lopes, A.A.C.; Passos, R.S.; Xavier, G.R.; Fernandes, M.F.; Mendes, I.C.; Junior, F.B.R. Estrutura metabólica e genética de comunidades bacterianas em solo de cerrado sob diferentes manejos. Pesq. agropec. bras. 2012; 47 (2).

13. Piotrowska, M., Sliżewska, K., Nowak, A., Zielonka, L., Zakowska, Z., Gajęcka, M., \& Gajęcki, M. The effect of experimental fusarium mycotoxicosis on microbiota diversity in porcine ascending colon contents. Toxins. 2014; 6(7).

14. ANVISA. Agência Nacional de Vigilância Sanitária, Detecção e identificação de bactérias de importância médica - Módulo V. 2004.

15. Taneja, N.,Kaur, H. Insights into Newer Antimicrobial Agents Against Gram-negative

Bacteria. Microbiology insights. 2016; 9 9: 9 -19. doi:10.4137/MBI.S29459

16. Martinelli Filho,A., Graner, M., Barbin, D., Silveira, E.T.F. Contagem total de bactérias $\varepsilon$ enumeração de coliformes em cortes de varejo de carne bovina $\varepsilon$ em equipamentos de supermercados. E.S.A. Luiz de Queiroz. 1977; 34: 231-245.

17. Boulange-Petermann, L.; Robine E.; Ritoux, S.; Cromieres B. Kinetics of bacterial survival on polymer coatings with particular reference to indoor air quality. Biofouling. 2004.

18. Albuquerque, A. C., Andrade, C., Neves, B. Biocorrosão - da integridade do biofilme à integridade do material. Corros. Prot. Mater. 2014; 33;18-23.

19. Lima, J. L. C., Alves, L. R. A. Paz, J. N. P. Rabelo, M. A. Maciel, M. A. V. Morais, M. M. C. Rev. bras. ter. intensiva. 2017; 29(3). 
20. Pieniz, S. Rodrigues, D.F., Arndt, R.M. Mello, J.F. Rodrigues, K.L., Andrezza, R., Camargo , FAO, Brandelli, A. Braz. J. Biol. 2018.

21. Costerton. Bactérias biofilmes na natureza e doenças. Annu. Rev. Microbiologia, 1987.

22. Chai $F$, Mathis N, Blanchemain N, Meunier C, Hildebrand HF. Osteoblast interaction with DLCcoated $\mathrm{Si}$ substrates. Acta Biomater. 2008; 4(5): 1369-81

23. Cassenego, P.V., Ellwanger, J., D'Azevedo, P.A.Virulência e formação de biofilme microbiano por Enterococcus faecalis isolados de swabs cloacais de frangos de corte infectados com Eimeria spp. Pesq. Vet. Bras. 2013; 33(12):1433-1440.

24. DOSANI, S. Penicillin man: Alexander Fleming and the Antibiotic Revolution. BMJ. 2005;330:50.

25. Kan, A., Del Valle, I., Rudge, T., Federici, F., \& Haseloff, J. Intercellular adhesion promotes clonal mixing in growing bacterial populations. Journal of the Royal Society Interface. 2018. 